\title{
Circular Piezoelectric Accelerometer for High Band Width Application
}

Hindrichsen, Christian Carstensen; Larsen, Jack; Lou-Møller, Rasmus; Hansen, K.; Thomsen, Erik Vilain

Published in:

IEEE Sensors 2009

Link to article, DOI:

10.1109/ICSENS.2009.5398277

Publication date:

2009

Document Version

Publisher's PDF, also known as Version of record

Link back to DTU Orbit

Citation (APA):

Hindrichsen, C. C., Larsen, J., Lou-Møller, R., Hansen, K., \& Thomsen, E. V. (2009). Circular Piezoelectric Accelerometer for High Band Width Application. In IEEE Sensors 2009 IEEE.

https://doi.org/10.1109/ICSENS.2009.5398277

\section{General rights}

Copyright and moral rights for the publications made accessible in the public portal are retained by the authors and/or other copyright owners and it is a condition of accessing publications that users recognise and abide by the legal requirements associated with these rights.

- Users may download and print one copy of any publication from the public portal for the purpose of private study or research.

- You may not further distribute the material or use it for any profit-making activity or commercial gain

- You may freely distribute the URL identifying the publication in the public portal

If you believe that this document breaches copyright please contact us providing details, and we will remove access to the work immediately and investigate your claim. 


\section{Circular Piezoelectric Accelerometer for High Band Width Application}

\author{
C. C. Hindrichsen, J. Larsen, E. V. Thomsen \\ DTU Nanotech \\ Technical University of Denmark \\ Kgs. Lyngby, Denmark \\ christian.hindrichsen@nanotech.dtu.dk
}

\author{
K. Hansen \\ Ferroperm Piezoceramics A/S \\ Kvistgaard, Denmark
}

\author{
R. Lou-Møller \\ Insensor $\mathrm{A} / \mathrm{S}$ \\ Kvistgaard, Denmark
}

\begin{abstract}
An uniaxial bulk-micromachined piezoelectric MEMS accelerometer intended for high bandwidth application is fabricated and characterized. A circular seismic mass (radius $=1200 \mu \mathrm{m})$ is suspended by a $20 \mu \mathrm{m}$ thick annular silicon membrane (radius $=1800 \mu \mathrm{m})$. A $24 \mu \mathrm{m}$ PZT screen printed thick film is used as the sensing material on top of the silicon membrane. Accelerations in the out of plane direction induce a force on the seismic mass bending the membrane and a potential difference is measured in the out of plane direction of the stressed PZT. A resonance frequency of $23.50 \mathrm{kHz}$, a charge sensitivity of $0.23 \mathrm{pC} / \mathrm{g}$ and a voltage sensitivity of $0.24 \mathrm{mV} / \mathrm{g}$ are measured.
\end{abstract}

\section{INTRODUCTION}

Accelerometers utilizing the piezoelectric effect are preferred for some specific applications, due to good linearity, long term stability and better temperature stability compared to capacitive and piezoresistive accelerometers. Piezoelectric accelerometers operate in one of three modes; shear mode, compression mode and bending mode. Micro Electro Mechanical System (MEMS) accelerometers using the piezoelectric effect all operate in the bending mode which is easiest to realize using silicon based planar processing. When the seismic mass of the accelerometer is accelerated a piezoelectric film situated on a spring, typically a beam or membrane, is stressed. The charge generated in the stressed piezoelectric material gives rise to a potential difference measured between two electrodes on each side of the piezoelectric thick film.

MEMS based piezoelectric accelerometers are smaller, have lower costs and are comparable in performance to the piezoelectric accelerometers commercially available today [1]. A potential application for the type of accelerometer presented here is machine monitoring [2].

This project is a collaboration with InSensor $\mathrm{A} / \mathrm{S}$ and Ferroperm Piezoceramics A/S and is supported by "The Danish National Advanced Technology Foundation".
A MEMS accelerometer with piezoelectric thin film and a silicon substrate $(<5 \mu \mathrm{m}$ thick) has been presented by Wang et al. [3]. The only accelerometer with piezoelectric thick film ( $>5 \mu \mathrm{m}$ thick) has been presented by Beeby et al. [4]. Piezo electric thin film in MEMS has been studied intensively [5]. However for high bandwidth applications accelerometers with piezoelectric thick films result in significant higher voltage sensitivity for a given bandwidth. The piezoelectric thick film is applied onto the silicon substrate wafer using the well studied screen printing technique [6]. The piezoelectric ceramic $\mathrm{Pb}\left(\mathrm{Zr}_{\mathrm{x}} \mathrm{Ti}_{1^{-}} \mathrm{x}\right) \mathrm{O}_{3}$ (PZT) has superior piezoelectric properties compared to other piezoelectric materials. The type of PZT used in this work is the hard doped PZ26 from Ferroperm Piezoceramics A/S

Wang et al. [3] presents two different accelerometer designs are presented; a square mass suspended by four beams and a circular seismic mass suspended by an annular membrane. Both designs can be used for potential future triaxial accelerometer designs as shown in [7] and [8]. The circular membrane design is most compatible with the screen printing process used in this work as there are no through holes in the silicon substrate wafer. A more advanced pattern of the top electrode is easier to integrate in the circular design.

\section{ACCELEROMETER DESIGN}

A circular seismic mass is suspended by an annular membrane acting as the spring in the mass-spring system. The highly symmetric circular design reduces the unwanted cross axis sensitivity. The piezoelectric PZT is deposited on the front side of the membrane. Fig. 1 shows the accelerometer from the front and the back side. The backside of the accelerometer is protected by a pyrex wafer which also gives an optimal mounting surface. 


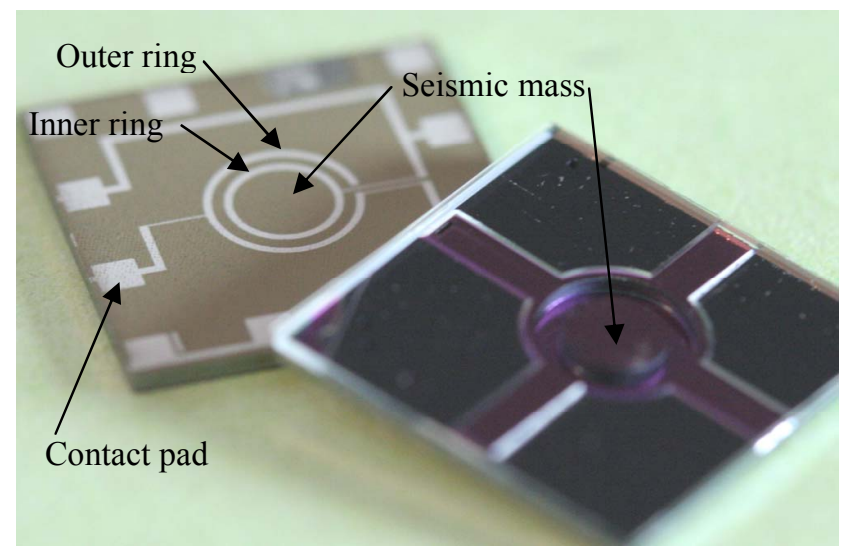

Figure 1. Two $1 \mathrm{~cm}^{2}$ accelerometer chips seen from the front side (left) and the backside with a bonded pyrex wafer for protection (right).

The accelerometer is operating in the 31 mode as the PZT is stressed in the in-plane direction and the potential difference is measured in the out of plane direction. The bottom electrode is covering the whole wafer surface except where the contact pads for the top electrodes are situated. This reduces the unwanted parasitic capacitance. The PZT material is patterned with the screen printing mesh in order to leave holes for contacting the bottom electrode. On top of the PZT the top electrode is patterned as two rings at the periphery of the annular membrane, where the induced stresses are highest. The two rings are referred to as inner and outer ring. The PZT beneath the inner and outer ring are polarized in opposite directions as shown in Fig 2 top. During operation the stress in the PZT beneath the inner and outer ring will be of opposite sign in the in-plane direction for an out of plane acceleration, see Fig. 2 bottom. The charge sensitivity is now approximately doubled when short circuiting the inner and outer in operation mode.
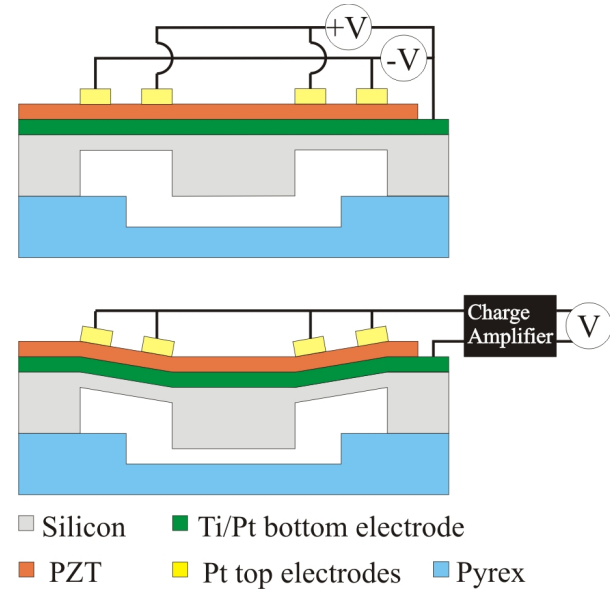

Figure 2. The PZT beneath the inner ring and the outer ring top electrode are polarized in opposite directions (top). The charge sensitivity is doubled when short circuiting the two rings in operational mode (bottom).

For all accelerometer designs there will be a compromise between high sensitivity and high resonance frequency. The dimensions of the accelerometer are chosen in order to have a resonance frequency above $20 \mathrm{kHz}$. The thickness of the PZT
TABLE I. The dimensions of the accelerometer.

\begin{tabular}{|c|c|}
\hline \multicolumn{2}{|c|}{ Dimensions $[\boldsymbol{\mu m}]$} \\
\hline Radius seismic mass & 1200 \\
\hline Height seismic mass & 500 \\
\hline Width of annular membrane & 600 \\
\hline Width of inner and outer electrode & 200 \\
\hline Width of accelerometer chip & 10000 \\
\hline Thickness of Si membrane & 20 \\
\hline Thickness of PZT thick film & 24 \\
\hline
\end{tabular}

thick film is optimized in order to have the neutral axis of the deflection in the interface of the PZT and the silicon substrate. All the dimensions of the accelerometer are shown in Tab. 1.

\section{FABRICATION PROCESS}

The accelerometer is fabricated with standard MEMS processing and the PZT thick film is deposited with the screen printing technique. A $500 \mu \mathrm{m}$ thick double-side polished (100) 4,' Silicon On Insulator (SOI) wafer is used as substrate material. All processes are on a wafer scale and are optimized for mass production.

An Advanced Silicon Etch (ASE) process is used for thinning down the membrane from the backside of the wafer. The desired thickness of the silicon membrane, $20 \mu \mathrm{m}$, is defined by the buried oxide of the SOI wafer. A dedicated diffusion barrier layer and bottom electrode layer is electron beam deposited on the front side. $\left|\mathrm{SiO}_{2}\right| \mathrm{Ti}|\mathrm{Pt}|$ with the thicknesses $|500| 50|500|$ in $\mathrm{nm}$ has proven to be good stack for the combined diffusion barrier and bottom electrode layer [4].

A PZT thick film is screen printed on a wafer scale on the front side of the patterned silicon substrate. Four layers are screen printed on top of each other resulting in a final layer thickness of $24 \mu \mathrm{m}$. The PZT thick film is patterned with holes, using a fine $77 \mathrm{~T}$ polyester mesh for contacting the bottom electrode. The ceramic PZT paste is sintered for $1 \mathrm{~h}$ at $850^{\circ} \mathrm{C}$. A $400 \mathrm{~nm}$ thick platinum thin film is evaporated onto the PZT thick film as a top electrode and patterned with a liftoff process. The process of applying the top electrode has been studied intensively and is described in detail in [9]. 50 $\mu \mathrm{m}$ deep cavities are etched into a pyrex wafer which is bonded onto the backside of the silicon wafer using anodic bonding. The PZT thick film is polarized on a semi wafer scale, where eight accelerometers are polarized at once as the electrode are connected on the wafer. The polarization is done at $150^{\circ} \mathrm{C}$ and with a field of $10 \mathrm{kV} / \mathrm{mm}$ between the bottom and top electrodes for 10 minutes. The final accelerometer is diced out into $10 \times 10 \mathrm{~mm}^{2}$ chips with a height of $1 \mathrm{~mm}$. A final product would also require a packaging solution for the front side increasing the total height.

\section{CHARACTERIZATION}

The piezoelectric accelerometer can be described as a non ideal capacitor which has a loss. The capacitance for the inner and the outer ring top electrodes are found to be 440 and 540 
$\mathrm{pF}$, respectively. Fig. 3 shows the measured impedance and phase as a function of frequency for the outer ring. A resonance - antiresonance shape is seen in the impedance measurements and a phase change of about four degrees is also seen. The mechanical first mode resonance frequency, $f_{r}$, is found at $23.50 \mathrm{kHz}$ and the antiresonance, $f_{a}$, peak is found at $23.65 \mathrm{kHz}$. The impedance at the resonance frequency, $Z_{r}$, is found to be $2.97 \mathrm{k} \Omega$. The loss of the accelerometer is described by the mechanical quality factor, $Q$, given as,

$$
Q=f_{a}^{2} /\left[2 \pi C_{o} f_{r} Z_{r}\left(f_{a}^{2}-f_{r}^{2}\right)\right]
$$

where $C_{o}$ is the capacitance of the outer ring. Inserting the measured values into equation (1), a quality factor of 340 is found. The coupling factor, $k_{\text {eff }}$, for the accelerometer is given as,

$$
k_{e f f}=\left[\left(f_{a}^{2}-f_{r}^{2}\right) / f_{r}^{2}\right]^{1 / 2}
$$

A coupling factor of $11.3 \%$ is found which is a bit lower compared to coupling for non fixed bulk PZT material which typically is around $40 \%$. As the PZT is fixed to the silicon substrate and not free to move a smaller coupling factor is expected.

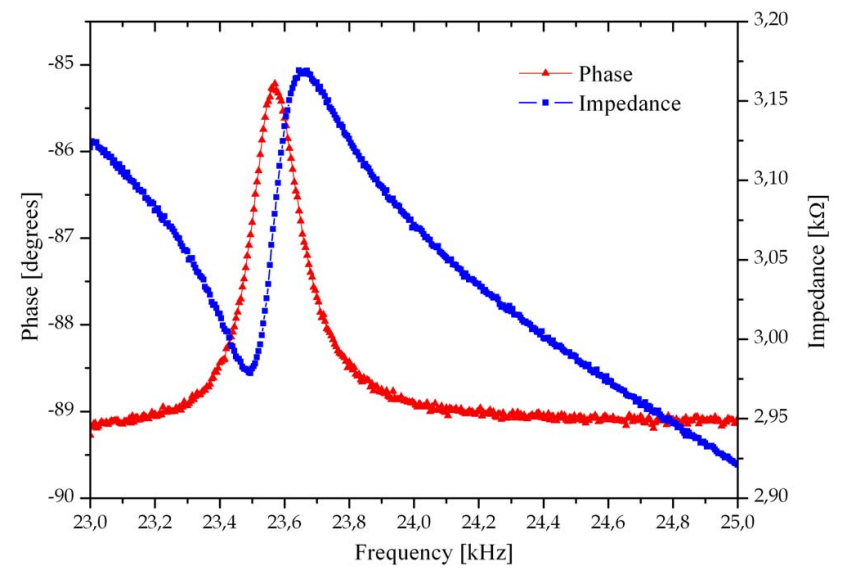

Figure 3. Mechanical resonance peak of the accelerometer is found at 23.50 $\mathrm{kHz}$ using impedance and phase measurements.

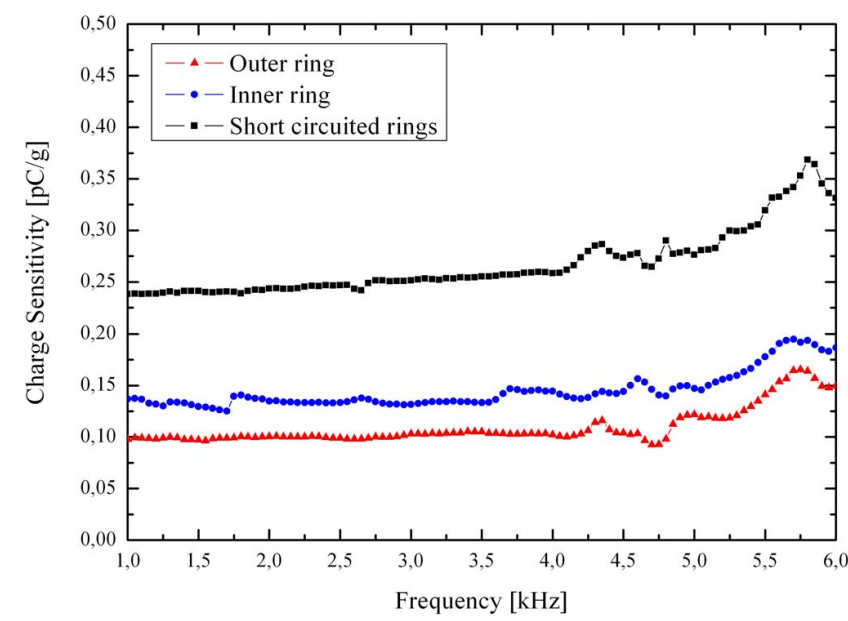

Figure 4. Charge sensitivity per acceleration, g, for inner / outer electrodes and the total charge sensitivity when short cicuited measured from $1-6 \mathrm{kHz}$ using the B\&K Mini Shaker 4810.

In order to find the frequency response and the sensitivity the accelerometer is mounted onto a shaker (B\&K Mini Shaker 4810), together with a reference accelerometer (B\&K Piezoelectric Accelerometer 8305). The shaker can be used in the frequency range from $1-15 \mathrm{kHz}$. The exact acceleration is measured with an reference simultaneously as the MEMS accelerometer and is used to determine the sensitivity. The oscillating shaker is driven by a wave generator (Agilent 33220A) through a voltage amplifier. For high g acceleration up to $45 \mathrm{~g}$ another shaker (B\&K Shaker 4813) is used instead which has a maximum stable oscillation frequency of $5 \mathrm{kHz}$. When reading out the voltage signal a charge amplifier converts the high impedance signal into a readable low impedance signal which can be transported over long distances. The converted output signal is read by a LabView program together with the applied vibration frequency of the shaker. All sensitivities presented are RMS values of the non amplified signal per $\mathrm{g}\left(9.82 \mathrm{~m} / \mathrm{s}^{2}\right)$.

Using the shaker setup a charge sensitivity of $0.13 \mathrm{pC} / \mathrm{g}$ and $0.10 \mathrm{pC} / \mathrm{g}$ for the inner and outer ring respectively are found for an oscillation frequency $1 \mathrm{kHz}$. Short circuited the total charge sensitivity is $0.23 \mathrm{pC} / \mathrm{g}$. Fig. 4 shows the charge sensitivity in the bandwidth from 1 to $6 \mathrm{kHz}$ found using the B\&K Mini Shaker 4810. The charge sensitivity for the inner and the outer ring are measured separately and when short circuited. It is clear that when short circuited the measured charge sensitivity corresponds to the sum of the charge sensitivity of the inner and the outer ring. This proves that when polarizing the PZT thick film in two opposite directions the charge sensitivity can be approximately doubled. 


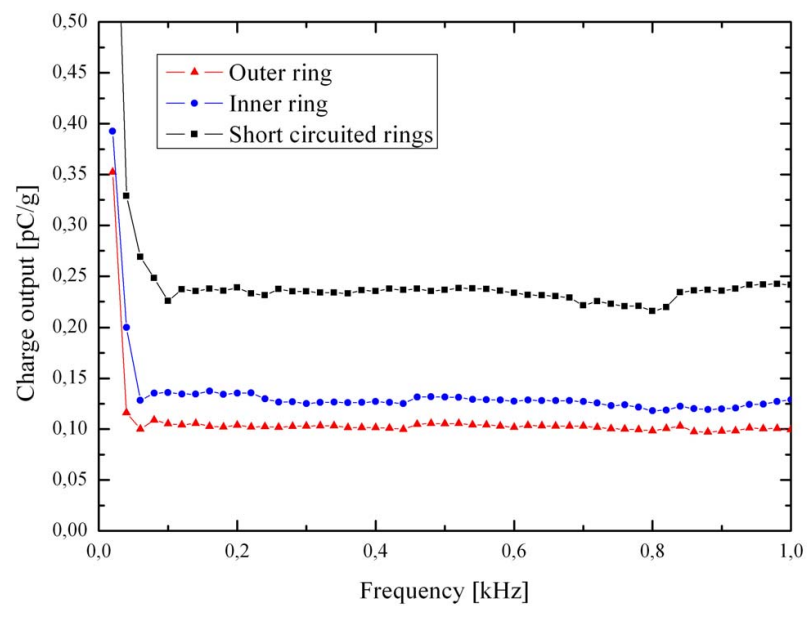

Figure 5. Charge sensitivity per acceleration, g, for inner / outer electrodes and the total charge sensitivity when short cicuited measured from $0-1 \mathrm{kHz}$ using the B\&K Shaker 4813.

Fig. 5 shows the charge sensitivity in the bandwidth 0-1 $\mathrm{kHz}$ using the B\&K Shaker 4813. Below $0.1 \mathrm{kHz}$ the charge sensitivity can not be measured due to limitations of the charge amplifier. The deviation in sensitivity in the bandwidth from $0.1 \mathrm{kHz}$ to $4 \mathrm{kHz}$ is found to be below $9 \%$ with the sensitivity at $1 \mathrm{kHz}$ as a reference. Above $4 \mathrm{kHz}$ oscillations of the accelerometer mounting fixture and the connecting cables affect the measurement. The voltage sensitivity is found by dividing the charge sensitivity by the capacitance and is $0.24 \mathrm{mV} / \mathrm{g}$ for the short circuited rings.

For determining the acceleration range of the accelerometer the B\&K Shaker 4813 is used. Fig. 6 shows the voltage output for the two short circuited rings as a function of acceleration from $0-45 \mathrm{~g}$ at a fixed frequency of $1 \mathrm{kHz}$. At accelerations below $0.5 \mathrm{~g}$ the noise level become dominant and the output voltage is no longer linear proportional to the applied acceleration. Up to the maximal acceleration of the shaker at $45 \mathrm{~g}$ the accelerometer has a linear response.

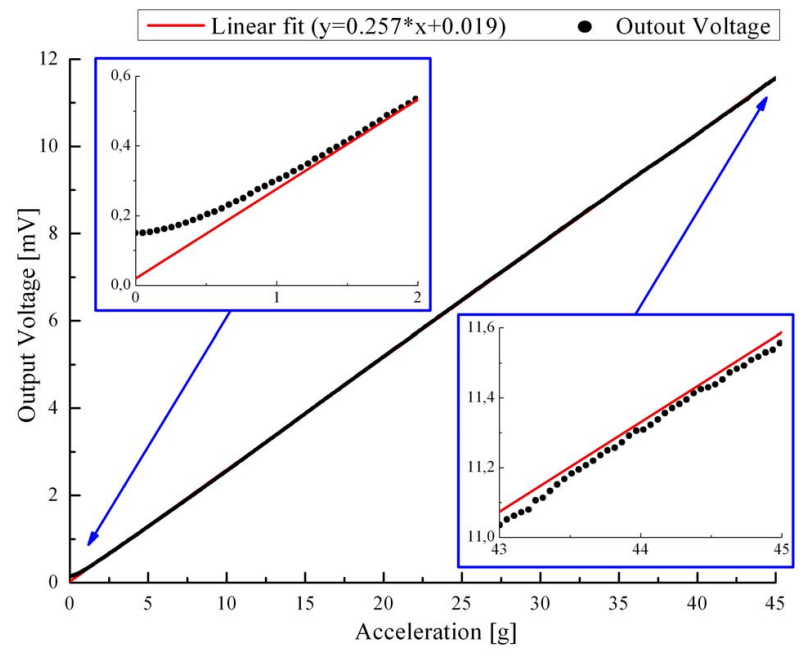

Figure 6. The accelerometer is tested up to $45 \mathrm{~g}$ with a deviation from the linear fit of less than $2 \%$. The lower limit acceleration is around $1 \mathrm{~g}$.
The deviation from the linear fit made in the $0.5-1 \mathrm{~g}$ range is less than $2 \%$ which is an acceptable level of linearity. With the given setup the cross axis sensitivity is found to be below the noise level and could therefore not be measured.

The analytical model presented by Che et al. [7] is used to evaluate the measured sensitivities and resonance frequency. The model gives a charge and voltage sensitivity for the short circuited rings of $0.30 \mathrm{pC} / \mathrm{g}$ and $0.29 \mathrm{mV} / \mathrm{g}$ respectively which deviates $23 \%$ and $17 \%$ from the measured respectively. The modeled resonance frequency is found to be $35.6 \mathrm{kHz}$ which deviates 34\% from the measured resonance frequency. FEM models made are in good agreement with the analytical model. The relatively high deviations between the measured and modeled values are due to an uncertainty regarding the mechanical properties of the PZT thick film.

\section{CONCLUSION}

A piezoelectric uniaxial accelerometer based on a circular design has been presented. The highly symmetric design reduces cross axis sensitivity and makes the deposition of the PZT thick film easier compared to a design with through holes in the substrate wafer. A simple and all batch process has been used to fabricate the accelerometer on a wafer scale included part of the packaging, namely a pyrex wafer anodic bonded to the backside. The accelerometer has a charge sensitivity and voltage sensitivity of $0.23 \mathrm{pC} / \mathrm{g}$ and $0.24 \mathrm{mV} / \mathrm{g}$ with a deviation of less than $9 \%$ in the bandwidth $0.1-4 \mathrm{kHz}$. The resonance frequency is found at $23.50 \mathrm{kHz}$ and a linear response up to $45 \mathrm{~g}$ is found.

\section{REFERENCES}

[1] P. Scheeper, J. O. Gullv, L. M. Kofoed, A piezoelectric triaxial accelerometer, J. Micromech. Microeng. 6, 1996, pp. 131-133

[2] J. Robinson, Using Accelerometers to Monitor Complex Machinery Vibration, Sensors, June, 1997, pp. 36-42

[3] L. P. Wang, R. A. Wolf, Y. Wang, K. K. Deng, L. Zou, R. J. Davis, S. Troiler-McKinstry, Design, Fabrication, and Measurementof HighSensitivity PiezoelectricMicroelectromechanical Systems Accelerometers, Journal of Microelectromechanical Systems, Vol .12 No. 4, 2003, pp. 433-439

[4] S. P. Beeby, J. N. Ross, N. M. White; Journal of Micromech Michroeng., Vol. 10, 2000, pp. 322-328

[5] S. Trolier-Mckinstry, P. Muralt, Thin film piezoelectrics for MEMS, Journal of Electroceramics, Vol.12, 1-2, 2004, pp. 7-17

[6] R. Lou-Moeller, C. C. Hindrichsen, L. H. Thamdrup, T. Bove, E. Ringgaard, A. F. Pedersen, E. V. Thomsen, Screen-Printed Piezoceramic Thick Films for Miniaturised Devices, Journal of Electroceramics, Vol. 19, Issue 4, 2007, pp. 333-338

[7] L. Che, E. Halvorsen, X. Chen, Modeling of a Highly Sensitive Piezoelectric Triaxial Accelerometer, Eurosensors 2008 conference proceedings, 2008, pp. 89-92

[8] C. C. Hindrichsen, N. S. Almind, S. H. Brodersen, O. Hansen, E. V. Thomsen, Analytical Model of a PZT Thick-Film Triaxial Accelerometer for Optimum Design, IEEE Sensors Journal, Vol.9 Issue.4, 2009, pp. 419-429

[9] C. C. Hindrichsen, T. Pedersen, K. Hansen, R. Lou-Moller, E.V. Thomsen, Investigation of Top/Bottom Electrode and Diffusion Barrier Layer for PZT Thick Film MEMS Sensors, Ferroelectrics, Vol.367, 2008, pp. 201-214 